\title{
INTERAKSI GENETIK X LINGKUNGAN DAN STABILITAS JUMLAH BUAH 11 AKSESI PINANG LOKAL DENGAN PENDEKATAN PARAMETRIK
}

\author{
Genetic x Environment Interaction and Stability Number of Fruit 11 Local Areca Accessions \\ with Parametric Approach \\ Muhammad Roiyan Romadhon, Meity Aneke Tulalo \\ Balai Penelitian Tanaman Palma \\ Jln. Raya Mapanget, Kotak Pos 1004 Manado 95001 \\ *Email korespondensi: roiyannurdin041924254@gmail.com
}

\section{Diterima 14 September 2020/Disetujui 2 Oktober 2020}

\begin{abstract}
ABSTRAK
Pinang merupakan tanaman tahunan yang memilki banyak manfaat dan ekonomi tinggi. Kebutuhan buah pinang untuk industri menjadi kendala karena baru dua varietas pinang yang dilepas dan masih sedikit petani yang menanam pinang. Eksplorasi kandidat pinang unggul menjadi salah satu cara untuk mengatasi masalah tersebut. Penelitian ini bertujuan untuk mengetahui stabilitas dan adaptabilitas 11 pinang lokal terhadap jumlah buah. Penelitian dilakukan di KP Kayuwatu selama 4 tahun dari tahun 2014-2017. Rancangan Penelitian yang digunakan yaitu Rancangan Acak Kelompok (RAK) 4 ulangan dengan 15 tanaman sampel. Hasil penelitian menunjukkan bahwa ada interaksi genetik x lingkungan dua belas aksesi pinang terhadap jumlah buah. Aksesi Malinow 2 merupakan aksesi yang stabil berdasarkan analisis stabilitas Finlay Wilkinson dan Eberhart Russel dan dapat tumbuh di lingkungan marginal, sedangkan Aksesi Huntu 1 dan Galangsuka merupakan aksesi yang stabil di lingkungan optimal.
\end{abstract}

Kata Kunci: adaptasi, deviasi, eksplorasi, ragam gabungan, regresi

\begin{abstract}
Areca is an annual plant that has many benefits and a high economy. The need for areca nuts for industry is a challenge because only two varieties have been released and little farmers who plant areca nuts. Exploration of superior areca candidates are one way to overcome this problem. This aim of research is to determine the stability and adaptability of 11 local areca nuts to the number of fruit. This research was conducted at Kayuwatu Expermental Farm for 4 years from 2014-2017. The experimental design used was Randomized Complete Block Design ( $R C B D) 2$ replications with 15 sample plants. The result of the researchshowed that Malinow 2 accession is a stable accession based on the stability analysis of Finlay Wilkinson and Eberhart Russel and can grow in a marginal environment, while Huntu 1 and Galangsuka Accession is a stable accession in optimal environment.
\end{abstract}

Keywords: adaptation, combined varian, deviation, exploration, regression 


\section{PENDAHULUAN}

Pinang merupakan salah satu jenis tanaman palma yang memiliki potensi untuk dikembangkan dan bernilai ekonomi. Pinang memiliki banyak manfaat untuk dunia industri dan kesehatan. Bhat (2019) menyatakan bahwa pinang dapat berguna untuk bahan baktu industri pengobatan karena mengandung senyawa hidroalkohol dan polifenol (anti bakteri), alkoloid dan flavonoid (anti jamur), arecolin (anti diabet), butanol (anti malaria), aceton dan dimetilsufoksida (anti kanker), aspirin (anti imflamasi), dan hidroalkohol (anti migrain). Kebutuhan buah pinang dalam jumlah yang banyak harus diperhitungkan sehingga kebutuhan buah pinang secara kontinyu dapat terpenuhi. Kemendag (2017) menyatakan bahwa permintaan kebutuhan pinang per bulan untuk pasar Asia Selatan sebesar 9000 ton sedangkan Indonesia baru menyuplai sebesar sekitar 3600-4500 ton pinang.

Karakter jumlah buah dan bobot buah merupakan parameter penting untuk produktivitas tinggi. Eksplorasi, koleksi dan evaluasiterhadap plasma nutfah pinang dariberbagaidaerah di Indonesia (Jambi, Aceh, Papua, Deli Serdang, dan Gorontalo) telah dilakukan dengan tujuan untuk mengkonservasi serta mendapatkan aksesiaksesi pinang dengan karakter yang potensial untuk_dikembangkan_sesuai kebutuhan. Hasil eksplorasi dan karakterisasi tersebut telah menghasilkan dua varietas pinang yang telah dilepas oleh Menteri Pertanian sebagai varietas unggul yaitu Pinang Betara asal Jambi dan Pinang Emas asal Sulawesi Utara. Pinang Betara mempunyai keunggulan jumlah buah per pohon per tahun sebanyak 660 butir sedangkan Pinang Emas memliki batang lebih pendek dan umur berbunga 4-5 tahun.

Salah satu tujuan program pemuliaan tanaman adalah mendapatkan varietas unggul dengan produksi buah tinggi. Tujuan pemuliaan pinang dalam beberapa tahun terakhir difokuskan untuk jumlah buah yang banyak, dan cepat berbuah. Selain potensi hasil yang tinggi, suatu aksesi diharapkan stabil dan beradaptasi luas terhadap perubahan lingkungan. Rahayu et al. (2013) menyatakan bahwa ekspresi fenotipe tanaman dipengaruhi tiga sumber keragaman yaitu genetik, lingkungan, dan interaksi genetik $\mathrm{x}$ lingkungan. Yuliasti (2017) menyatakan bahwa adanya interaksi genetik x lingkungan dapat menentukan genotipe yang dapat beradaptasi di lingkungan yang berbeda dan membantu pemulia untuk menentukan genotipe yang sesuai dengan lingkungan target (Meena et al. 2019). Karakter hasil sebagai karakter kuantitatif dipengaruhi oleh genetik dan lingkungan sehingga seleksi yang tepat dilakukan di berbagai lingkungan untuk mengetahui kestabilan suatu genotipe (Ajmera 2017). Adanya interaksi genetik $\times$ lingkungan memainkan peran penting dalam identifikasi genotipe stabil untuk digunakan selanjutnya sebagai kultivar komersial (Shrestha et al. 2012).

Uji daya hasil terhadap jumlah buah dan bobot buah pada aksesi pinang lokal merupakan karakter yang paling penting untuk mengetahui stabilitas hasil melalui karakter jumlah buah sehingga dapat dilepas menjadi varietas unggul nasional. Penelitian ini bertujuan untuk mengetahui stabilitas dan adaptabilitas sebelas aksesi plasma nutfah pinang berdasarkan Finlay Wilkinson.

\section{BAHAN DAN METODE}

Penelitian_dilaksanakan di KP Kayuwatu Balai PenelitianTanaman Palma sejak tahun 2014-2017. Bahan yang digunakanadalah 11aksesi plasma nutfah pinang yang merupakan hasil eksplorasi dari beberapa daerah di Indonesia dengan umur tanam tahun 2010 (Tabel 1). Rancangan percobaan yang digunakan adalah Rancangan Acak Kelompok (RAK) dengan 4 ulangan dan satu faktor yaitu aksesi pinang. Tanaman sampel yang 
digunakan masing-masing aksesi sebanyak 15 tanaman dengan jarak tanam $3 \mathrm{~m} \times 2 \mathrm{~m}$. Data jumlah buah diuji dengan uji beda nilai tengah (anova) dan dianalisis menggunakan program aplikasi SAS 9.0. Data yang memiliki ragam yang homogen diuji dan dianalisis dengan menggunakan analisis ragam gabungan untuk mempartisi komponen ragam genotipe, lingkungan, dan pengaruh interaksi genetik $\mathrm{x}$ lingkungan.

Tabel 1. Sebelas aksesi dan asal daerah

\begin{tabular}{lcc}
\hline No & Aksesi & Asal Daerah \\
\hline 1 & Galang Suka & Deli Serdang \\
2 & Huntu 1 & Gorontalo \\
3 & Huntu 2 & Gorontalo \\
4 & Malinow 1 & Sulawesi Utara \\
5 & Malinow 2 & Sulawesi Utara \\
6 & Mongkonai & Sulawesi Utara \\
7 & Rasau Jaya & Kalimantan Barat \\
8 & Sakernan & Jambi \\
9 & Singkawang 1 & Kalimantan Barat \\
10 & Singkawang 2 & Kalimantan Barat \\
11 & Tarean & Deli Serdang \\
\hline
\end{tabular}

Analisis stabilitas dilakukan dengan menggunakan model stabilitas yang diusulkan oleh Finlay dan Wilkinson (1963). Stabilitas Finlay Wilkinson berdasarkan nilai koefisien regresi (bi) tidak berbeda nyata dengan 1 dinyatakan sebagai stabil.

$$
b_{i}=\sum_{j=1}^{q}\left(X_{i j}-\bar{X}_{i .}\right)\left(\bar{X}_{. j}-\bar{X}_{-}\right) / \sum_{j=1}^{q}\left(\bar{X}_{. j}-\bar{X}_{-}\right)^{2}
$$

Stabilitas menurut Eberhart-Russel menggunakan menggunakan parameter koefisien $b_{i}$ dan deviasi dari regresi. Model regresi yang disarankan oleh (Eberhart dan

\section{HASIL DAN PEMBAHASAN}

Pengujian stabilitas dan adaptabilitas dilakukan mulai tahun 2014 sampai 2017. Tabel 2 menunjukkan minimum dan maksimum curah hujan, serta rataan curah hujan tahunan untuk musim tumbuh. Rataan curah hujan paling tinggi yaitu pada tahun 2017. Perbedaan yang cukup tinggi antar lingkungan tumbuh mempengaruhi pembentukan buah pada
Russell 1966) memberikan koefisien regresi linier $\left(b_{i}\right)$ sebagai indikasi respons dari genotipe dengan indeks lingkungan dan penyimpangan dari titik tengah regresi $\left(\mathrm{S}^{2} \mathrm{~d}\right)$, sebagai kriteria stabilitas seperti yang disarankan oleh Becker dan Léon (1988). Jika nilai bi<1 menunjukkan suatu genotipe memiliki stabilitas di atas rata-rata. Nilai bi=1 menunjukkan suatu genotipe memiliki stabilitas standar. Nilai bi>1 menunjukkan suatu genotipe memiliki stabilitas di bawah rata-rata.

$$
\delta_{i}^{2}=\frac{1}{(q-2)}\left[\sum_{j=1}^{q}\left(X_{i j}-X_{i .}\right)^{2}-\beta_{i}^{2} \sum_{j=1}^{q}\left(X_{. j}-X_{. .}\right)^{2}\right.
$$

suatu tanaman. Faktor lingkungan yang berbeda menjadi salah satu penentu keragaman karakter agronomi yang muncul salah satunya jumlah buah. Adanya pengaruh curah hujan yang berbeda pada tiap tahun menyebabkan munculnya interaksi GxE. Istoqomah dan Harianto (2018) menyatakan bahwa munculnya buah disebabkan karena faktor iklim seperti suhu minimun, curah hujan, hari hujan, dan lama penyinaran. 
Tabel 2. Deskripsi 4 lingkungan yang digunakan untuk evaluasi 11 aksesi selama 4 tahun (2014-2017)

\begin{tabular}{lrrrrr}
\hline \multirow{2}{*}{ Lingkungan } & \multirow{2}{*}{ Tahun } & \multicolumn{3}{c}{ Curah hujan (mm) } & \multirow{2}{*}{ Hujan tahunan (mm) } \\
\cline { 3 - 4 } & & min & \multicolumn{2}{c}{ Maks } & \\
\hline L1 & 2014 & 26 & 583 & 196.83 \\
L2 & 2015 & 3 & 525 & 196.33 \\
L3 & 2016 & 10 & 651 & 249.75 \\
L4 & 2017 & 126 & 639 & 283.50 \\
\hline
\end{tabular}

Analisis Ragam Gabungan

Analisis gabunganGenotipe (G), lingkungan (E) dan interaksi genotipe $\times$ lingkungan $(\mathrm{GxE})$ sangat signifikan( $\mathrm{P}$ $<0,001$ ) untuk jumlah buah (Tabel 3).
Adanya efek interaksi GxE yang ditunjukkan pada kuadrat tengah (KT) untuk karakter jumlah buah paling tinggi di antara sumber keragaman lain mencerminkan perbedaan aksesi terhadap adaptasilingkungan yang berbeda.

Tabel 3. Analisis ragam gabungan 11 aksesi pinang lokal terhadap jumlah buah

\begin{tabular}{lrrrr} 
Sumber Keragaman & Db & Jumlah Kuadrat & Kuadrat Tengah & Pr > F \\
\hline Model & 51 & 56104.61 & 1100.09 & $<.0001$ \\
Lingkungan & 3 & 10955.20 & 3651.73 & $<.0001$ \\
Ulangan(Lingkungan) & 8 & 821.27 & 102.66 & 0.933 \\
Aksesi & 10 & 15105.94 & 1510.59 & $<.0001$ \\
Lingkungan*Aksesi & 30 & 29222.20 & 974.07 & $<.0001$ \\
Galat & 80 & 22146.50 & 276.83 & \\
Total & 131 & 78251.11 & & \\
\hline
\end{tabular}

Interaksi $\mathrm{G} \times \mathrm{E}$ yang sangat signifikan menunjukkan bahwa aksesi dapat dipilih untuk adaptasi ke lingkungan spesifik. Xu et al.(2014) dalam efek interaksi $\mathrm{G} \times \mathrm{E}$ dari singkong genotipe menyebabkan perbedaan hasil umbi per pohon. Interaksi genetik $x$ lingkungan yang signifikan menunjukkan aksesi itu merespons secara berbeda terhadap variasi lingkungan. Jumlah kuadrat yang tinggi untuk aksesi menunjukkan bahwa aksesi beragam. Hal ini sesuai dengan penelitian Fentie et al. (2013) pada hotong dan Chemeda (2018) pada hasil bulir padi.

Rataan Jumlah Buah Setiap Lingkungan Rataan jumlah buahpada tahun 2014 pada lingkungan 1 lebih tinggi dari lingkungan lain (Tabel 4).

Tabel 4. Kisaran jumlah buah aksesi pinang pada empat lingkungan (2014-2017) di Kebun Percobaan Kayuwatu

\begin{tabular}{cccccc}
\hline Kode & Tahun & $\begin{array}{c}\text { Rataan Jumlah } \\
\text { Buah }\end{array}$ & $\begin{array}{c}\text { Maksimum Jumlah } \\
\text { Buah }\end{array}$ & Minimum Jumlah Buah & Kisaran \\
\hline Lingkungan 1 & 2014 & 50.61 & 106.11 & 19.95 & 86.16 \\
Lingkungan 2 & 2015 & 50.51 & 96.39 & 16.94 & 79.44 \\
Lingkungan 3 & 2016 & 42.34 & 52.74 & 25.94 & 26.79 \\
Lingkungan 4/ & 2017 & 28.26 & 41.05 & 10.08 & 30.96 \\
\hline
\end{tabular}


Kisaran yang tinggi pada jumlah buah pada lingkungan tersebut menunjukkan adanya variasi curah hujan yang tinggi pada lingkungan tersebut, sedangkan pada lingkungan yang range jumlah buahnya kecil menunjukkan variasi curah hujan kecil. Variasi curah hujan yang kecil menyebabkan pembentukan buah sedikit sehingga menyebabkan jumlah buah yang terbentuk sedikit. Sesuai dengan Tampubolon and Sihombing (2017), produksi pertanian dipengaruhi oleh curah hujan dan hari hujan.

\section{Stabilitas Finlay Wilkinson}

Stabilitas Finlay Wilkinson

ditentukan berdasarkan nilai $b_{i}$ (parameter koefisien regresi). Menurut Rahayu, stabilitas di bawah rata-rata menunjukkan bahwa genotipe tersebut peka terhadap perubahan lingkungan. Stabilitas di atas rata-rata menunjukkan genotipe tersebut tidak sensitif terhadap perubahan lingkungan (marginal). Aksesi yang stabil dengan jumlah buah yang tinggi yaituMalinow 2 karena nilai bi tidak berbeda nyata dengan 1 sedangkan untuk aksesi Huntu 1 dan Galangsuka termasuk kategori stabil dengan jumlah buah yang rendah (Tabel 5). Penelitian Purbokurniawanet al.(2014)menyatakan bahwa genotipe FM1R-1-3-1 sebagai genotipe yang stabil dengan nilai bi=1.31.

Tabel 5. Pendugaan stabilitas dan adaptabilitas paremeter jumlah buah untk 11 aksesi di 4 lingkungan

\begin{tabular}{|c|c|c|c|c|c|c|c|}
\hline Aksesi & $\begin{array}{c}\text { Lingkungan } \\
1\end{array}$ & $\begin{array}{c}\text { Lingkungan } \\
2\end{array}$ & $\begin{array}{c}\text { Lingkungan } \\
3\end{array}$ & $\begin{array}{c}\text { Lingkungan } \\
4\end{array}$ & $\begin{array}{c}\text { Rataan } \\
\text { Jumlah } \\
\text { Buah }\end{array}$ & bi & Sdi \\
\hline Tarean & 43.33 & 24.03 & 45.93 & 30.78 & 36.02 & $0.11^{*}$ & 0.01 \\
\hline Singkawang 2 & 43.39 & 44.72 & 52.74 & 31.78 & 43.16 & $0.53 *$ & 0.23 \\
\hline Singkawang 1 & 45.00 & 79.44 & 45.52 & 19.17 & 47.28 & $0.93^{*}$ & 3.71 \\
\hline Sakernan & 48.52 & 39.63 & 48.78 & 27.18 & 41.03 & $0.74 *$ & 0.01 \\
\hline Rasau Jaya & 28.22 & 16.94 & 43.52 & 10.08 & 24.69 & $0.38^{*}$ & 0.15 \\
\hline Mongkonai & 69.07 & 72.04 & 33.00 & 13.14 & 46.81 & $2.74 *$ & 7.50 \\
\hline Malinow 2 & 106.11 & 83.33 & 25.94 & 29.68 & 61.27 & $0.98 \mathrm{tn}$ & 8.90 \\
\hline Malinow 1 & 54.17 & 96.39 & 52.46 & 36.11 & 59.78 & $0.76^{*}$ & 3.11 \\
\hline Huntu 2 & 37.78 & 39.44 & 34.07 & 41.05 & 38.09 & $0.10^{*}$ & 0.01 \\
\hline Huntu 1 & 19.95 & 19.68 & 33.85 & 36.57 & 27.51 & $1.96 \mathrm{tn}$ & 1.93 \\
\hline Galang suka & 61.11 & 39.91 & 49.89 & 35.28 & 46.55 & $1.68 \mathrm{tn}$ & 1.96 \\
\hline Rataan Umum & & & & & 42.93 & & \\
\hline
\end{tabular}

\section{Stabilitas Ebehart dan Russel}

Hasil stabililtas dan adaptabilitas parameter jumlah buah pada empat lingkungan disajikan Tabel 5. Hasil rataan regresi gabungan menampilkan indeks lingkungan yang menunjukkan hasil dari dua parameter $b_{i}$ dan $S^{2} d_{i}$. Jika koefisien regresi (nilai b) tidak berbeda secara signifikan, genotipe beradaptasi dalam semua lingkungan. Genotipe dengan $b>1.0$ lebih beradaptasi dengan lingkungan optimal, sedangkan genotipe dengan $\mathrm{b}<1.0$ beradaptasi dengan lingkungan suboptimal. Pengujian 11 aksesi menunjukkan Aksesi Rasau Jaya sebagai aksesi yang stabil pada lingkungan optimal dengan nilai bi $>1$ serta nilai $\mathrm{R}^{2}$ sebaesar $62.79 \%$. Karadavut dan Akilli (2012)menyatakan bahwa nilai $\mathrm{R}^{2}$ dapat digunakan sebagai konfirmasi kandidat yang diuji stabiljika diatas $50 \%$. Aksesi Malinow 2 sebagai aksesi yang stabil di lingkungan marginal dengan nilai 
bi $<1$ (adaptasi luas) sedangkan Aksesi Huntu 1 dan Galangsuka memiliki stabilitas di bawah rata-rata karena nilai bi $<1$.

\section{KESIMPULAN}

Aksesi Malinow 2 merupakan aksesi yang memiliki jumlah buah paling tinggi sebanyak 61.27 buah dibandingkan semua aksesi yang diuji. Aksesi Malinow 2 merupakan Aksesi yang stabil berdasarkan analisis stabilitas Finlay Wilkinson dan Eberhart Russel dan dapat tumbuh di lingkungan marginal, sedangkan Aksesi Huntu 1 dan Galangsuka merupakan aksesi yang stabil di lingkungan optimal.

\section{DAFTAR PUSTAKA}

Ajmera S. 2017. Studies on stability analysis for grain yield and its attributes in rice (Oryza sativa L.) genotypes. International Journal of Pure \& Applied Bioscience 5(4): 892908.

Bhat SK. 2019. Arecant (Areca catechu L): a store house of medicines. Indian Journal of Arecanut, Spices and Medicinal Plants. 21(1): 40-51.

Becker HC, Léon J. 1988. Stability analysis in plant breeding. Plant Breeding. 101(1): 1-23.

Chemeda G. 2018. Genotype x environment interaction and yield stability in improved rice varieties (Oryza sativa L.) tested over different locations in Western Oromia, Ethiopia. Global Journal of Science Frontier Research. 18(5): 38-44.

Eberhart SA, Russell WA. 1966. Stability parameters for comparing varieties.Crop Science 6(1): 36.

Fentie, Molla, Assefa A, Belete K. 2013. Ammi analysis of yield performance and stability of finger millet genotypes across different environments. World Journal of Agricultural Sciences. 9(3): 231-37.

Finlay KW, WilkinsonGN. 1963. The
Analysis of adaptation in a plantbreeding programme. Australian Journal of Agricultural Research. 14(6): 742-54.

Istoqomah, Harianto, Didik. 2018. Kajian iklim (suhu kardinal dan curah hujan ) pada tanaman nanas (Ananas comosus L . ). Jurnal Produksi Tanaman. 6(6): 1005-11.

Kementerian perdagangan [Kemendag]. 2017. Peluang ekspor gambir dan pinang. Warta Ekspor. Mei: 2-18

Karadavut, Ufuk, Akillim A. 2012. Genotype-environment interaction and phenotypic stability analysis for yield of corn cultivar.Greener Journal of Agricultural Sciences 2(9): 220-23.

Miftahorrachman, Salim, dan Matana Y. 2015. Teknologi Budidaya dan Pascapanen Pinang. IAARD press: Jakarta

Meena, Monika. 2019. Analysis for seed yield and yield component ajwain (Trachyspermum ammi L .). Electronic Journal of Plant Breeding. 10(3): 1194-1199.

Purbokurniawan, Bambang SP, Wirnas D, Dewi S. 2014. Potensi dan stabilitas hasil, serta adaptabilitas galur-galur padi gogo tipe baru hasil kultur antera. Jurnal Agronomi Indonesia. 42(1): 916.

Rahayu S, Dewi AK, Yulidar, Wirnas D, Aswidinnoor H. 2013. Analisis stabilitas dan adaptabilitas beberapa galur padi dataran tinggi hasil mutasi induksi.A Scientific Journal for The Applications of Isotopes and Radiation. 9(2): 81-90.

Shrestha S, Asch F, Dusserre J, Ramanantsoanirina A, Brueck H.2012. Climate effects on yield components as affected by genotypic responses to variable environmental conditions in upland rice systems at different altitudes. Field Crops Research. 134: 216-228.

Tampubolon, Koko, Sihombing FN. 2017. Pengaruh curah hujan dan hari hujan 
terhadap produksi pertanian serta hubungannya dengan PDRB atas harga berlaku di Kota Medan. Jurnal Pembangunan Perkotaan 5(1): 35-41.
Xu FF, Tang FF, Shao YF, Chen YL, Tong C, Bao JS. 2014. Genotype $\times$ environment interactions for agronomic traits of rice revealed by association mapping. Rice Science 21(3): 133-141. 